\title{
Effectiveness and Safety of Romiplostim Among Patients with Newly Diagnosed, Persistent and Chronic Immune Thrombocytopenia in European Clinical Practice
}

Sara J. Snell Taylor (D) - Carrie M. Nielson · Alexander Breskin • Bradley Saul • Ying Yu • Naufil Alam •

Melissa Eisen · Jane Hippenmeyer · Ann Janssens • Tomas Kozak · Helen A. Papadaki • Dominik Selleslag •

Jean-Francois Viallard · Clemens Feistritzer · Georgia Kaiafa • Michael Kelsh • Karynsa Kilpatrick •

M. Alan Brookhart · Leah J. McGrath

Received: February 25, 2021 / Accepted: March 24, 2021 / Published online: April 18, 2021

(C) The Author(s) 2021

\section{ABSTRACT}

Introduction: Romiplostim has been approved in Europe since 2009 to treat patients with chronic primary immune thrombocytopenia (ITP). Using real-world data from seven European countries, we measured the effectiveness

Supplementary Information The online version contains supplementary material available at https:// doi.org/10.1007/s12325-021-01727-5.

S. J. Snell Taylor $(\bowtie) \cdot$ A. Breskin · B. Saul · Y. Yu • M. A. Brookhart · L. J. McGrath

NoviSci, Inc., 201 W Main St, Ste 101, Durham, NC 27701, USA

e-mail: staylor@novisci.com

C. M. Nielson · M. Eisen · M. Kelsh · K. Kilpatrick Amgen Inc., Thousand Oaks, USA

A. Breskin

Department of Epidemiology, University of North

Carolina at Chapel Hill, Chapel Hill, USA

N. Alam

Amgen Ltd, Uxbridge, UK

J. Hippenmeyer

Amgen Inc., Rotkreuz, Switzerland

A. Janssens

University Hospitals Leuven, Leuven, Belgium

T. Kozak

Charles University, Prague, Czech Republic and safety outcomes within 24 weeks following romiplostim initiation by duration of ITP: less than 3 months ("newly diagnosed"), 3-12 months ("persistent"), and more than 12 months ("chronic").

Methods: Adults with ITP and $\geq 1$ romiplostim administration between 2009 and 2012 were included. Endpoints included durable platelet response, median platelet count, rescue therapy, bleeding and adverse events. We used inverse probability of censoring weighted esti-

\section{H. A. Papadaki}

University Hospital of Heraklion, Heraklion, Greece

D. Selleslag

Algemeen Ziekenhuis Sint-Jan, Bruge, Belgium

J.-F. Viallard

Hospital du Haut Leveque, Pessac, France

\section{Feistritzer}

Universitätsklinik für Innere Medizin V Innsbruck, Innsbruck, Austria

G. Kaiafa

AHEPA University Hospital, Aristotle University of Thessaloniki, Thessaloniki, Greece

M. A. Brookhart

Department of Population Health Sciences, Duke

University, Durham, UK 
mators to estimate cumulative risk of each outcome. There were 64 newly diagnosed, 50 persistent, and 226 chronic ITP patients at romiplostim initiation.

Results: Durable platelet response at 24 weeks ranged from $32 \%$ [confidence interval (CI): $18-46 \%]$ in newly diagnosed patients to $53 \%$ (CI $37-68 \%$ ) in persistent patients. Median platelet count during follow-up ranged from 88 (CI $80-96) \times 10^{9} / \mathrm{L}$ in chronic patients to 131 (CI $102-160) \times 10^{9} / \mathrm{L}$ in newly diagnosed patients.

Conclusion: Regardless of ITP duration, over half of patients discontinued concomitant ITP medications. Few adverse events were observed. Although only approved for chronic patients, estimates of the romiplostim treatment effect were similar across patients being managed in European clinical practice, regardless of ITP duration at romiplostim initiation.

Keywords: Bleeding disorder; Immune thrombocytopenia; Real-world evidence; Romiplostim; Thrombopoietin receptor agonist

\section{Key Summary Points}

Newly diagnosed patients initiating romiplostim were older and had evidence of more severe thrombocytopenia than patients with persistent or chronic ITP.

In clinical practice, romiplostim was effective in raising platelet counts regardless of the duration of ITP, similar to previous clinical trials.

Adverse drug reactions were rare for patients with any ITP duration.

\section{DIGITAL FEATURES}

This article is published with digital features, including a summary slide, to facilitate understanding of the article. To view digital features for this article, go to https://doi.org/10.6084/ m9.figshare.14258513.

\section{INTRODUCTION}

Primary immune thrombocytopenia (ITP) is an acquired immune-mediated disorder characterized by platelet counts less than $100 \times 10^{9} / \mathrm{L}$ and increased risk of bleeding [1]. Primary ITP is relatively rare, with an annual incidence of 3.3/ 100,000 and prevalence of 9.5/100,000 adults [2]. Romiplostim was approved by the European Medicines Agency (EMA) on 4 February 2009 for the treatment of thrombocytopenia in adult patients with chronic ITP (currently defined as ITP lasting a duration of greater than 12 months) with insufficient response to prior therapy [3]. Romiplostim was approved by the United States Food and Drug Administration in 2008, and, in 2019, the label was revised to include all patients who have had an insufficient response to previous ITP treatments, regardless of ITP duration when the treatment is initiated [4].

Evidence from randomized clinical trials suggests romiplostim is effective at raising platelet levels among patients with chronic ITP as well as those in earlier phases (ITP $\leq 12$ months) [5]. For example, in an integrated analysis of nine studies involving 911 ITP patients treated with romiplostim, 53\% of those with newly diagnosed (ITP $<3$ months) or persistent (ITP 3-12 months), and $49 \%$ of those with chronic ITP achieved durable platelet response within 24 weeks of initiating romiplostim. In realworld clinical practice, estimates of romiplostim treatment effect have been examined overall [6]; however, such estimates of romiplostim treatment effect among patients by duration of ITP have not previously been described. The objective of this study was to describe patient characteristics, treatment patterns, and ITP-related health and safety outcomes in romiplostim users, both overall and stratified by duration of ITP at initiation of romiplostim. 


\section{METHODS}

\section{Study Design}

Data collection methodology has previously been described in Steurer et al. [6]; we provide a brief summary. Data were collected via chart review from clinical practices in seven European countries (Austria, Belgium, Czech Republic, France, Greece, Portugal, Sweden), with a maximum of 25 subjects enrolled per center. Participating practices comprised a mix of academic and non-academic centers. Each clinical site obtained Institutional Review Board (IRB)/Independent Ethics Committee (IEC) approval as required by the local institution(s). Starting with the first dose of romiplostim, follow-up data, including routine platelet count measurements, were abstracted weekly from medical charts when available. Demographics and prior health history were also abstracted from medical charts before romiplostim initiation. In our study, all analyses were stratified by duration of ITP at romiplostim initiation according to the following categories defined by the International Working Group [7, 8]: newly diagnosed ( $<3$ months since diagnosis), persistent (3-12 months since diagnosis), and chronic (>12 months since diagnosis).

\section{Cohort Selection}

As described in Steurer et al. [6], patients were eligible for the study if they were at least 18 years of age at romiplostim initiation, had primary ITP, and provided appropriate written informed consent. Patients were excluded from the study if, at the time of enrollment, the patient received or planned to receive pegylated recombinant human megakaryocyte growth and development factor, recombinant human thrombopoietin, or other thrombopoietin receptor agonists or related platelet products. Additionally, patients were excluded if they participated in any interventional clinical study or initiated romiplostim therapy before its commercial launch. Patients were enrolled from 2009 to 2012, with follow-up for this study ending in 2013.

\section{Follow-Up}

The index date was defined as the first date of romiplostim treatment. Patients were followed for 24 weeks or until the end of available data before 24 weeks (e.g., consent withdrawn or lost to follow-up) for descriptive analyses and were not censored for romiplostim discontinuation. For outcome analyses, patients were followed until the earliest of: end of the 24-week followup, end of available data, receipt of splenectomy, initiation of eltrombopag, occurrence of platelet transfusion, or lack of certain platelet measurements (Table S1). Additionally, overall platelet response, median overall platelet response, and first platelet response by week 24 were censored at the time of receipt of rescue therapy. Patients were defined as receiving rescue therapy if the therapy was received after (1) an initial platelet response (platelet count $\geq 50 \times 10^{9} / \mathrm{L}$ ) and subsequent loss of platelet response (platelet count $\leq 30 \times 10^{9} / \mathrm{L}$ ); or (2) treatment switch after no platelet response was observed; or (3) if therapies were introduced for active bleeding (Table S1). Rescue therapy of any type, specifically oral steroids as rescue therapy, Rho (D) immune globulin (intravenous anti-D), intravenous immunoglobulin (IVIg), intravenous steroids, or platelet transfusions as rescue therapy were recorded for each patient.

\section{Variables}

Baseline characteristics were described at romiplostim initiation and were abstracted using all available chart history unless otherwise specified. History of bleeding was defined as any bleeding event occurring in the 6 months before the index date. Active bleeding was defined as a bleeding event within 7 days before or on the index date. Thrombotic events at any point in the available chart history and liver events within 5 years of romiplostim initiation were coded using the Medical Dictionary for Regulatory Activities (MedDRA v.17.1), a clinically validated international medical terminology dictionary-thesaurus used by regulatory authorities and the biopharmaceutical industry 
for data entry and retrieval, as well as adverse event classification (Tables S2 and S3, respectively). Previously developed sets of embolic and thrombotic event terms from MedDRA were used to identify thrombotic events, including 317 terms related to thrombotic events (including but not limited to myocardial infarction, stroke, and venous thromboembolism; Table S2). Similarly, a previously developed set of 350 terms related to liver events were used, including but not limited to hepatitis, hepatic cirrhosis, and liver transplant (Table S3). The ITP medications that were captured included IV anti-D, autologous hematopoietic stem cell transplantation (AHSCT), azathioprine, alemtuzumab, corticosteroids (oral and intravenous), cyclophosphamide, cyclosporine, danazol, dapsone, eltrombopag, IVIg (a mixture of antibodies prepared from donated blood), mycophenolate, rituximab, and vinca-alkaloids. Medications were considered to be baseline if the start and end date of the medication occurred before the index romiplostim date. Medications were considered concomitant if the index romiplostim date fell between or on either the start or end date of the concomitant medication. Romiplostim discontinuation was documented as the date of the last dose administered in the medical record. Patients were considered to have refractory ITP if they (1) were splenectomized prior to romiplostim initiation, or (2) had three or more ITP therapies prior to romiplostim initiation.

\section{Outcomes}

Definitions of each outcome listed below and criteria for censoring are included in Table S1. Platelet-based outcomes included median overall platelet count, overall platelet response, and first platelet response, all of which were censored for rescue therapy. Median overall platelet count was defined as the median of all platelet count measurements during weeks 2-24 after index date. Overall platelet response was defined as the proportion of weekly platelet count measurements $\geq 50 \times 10^{9} / \mathrm{L}$ during weeks 2-24 after the index date. First platelet response was defined as the first instance of a platelet count $\geq 50 \times 10^{9} / \mathrm{L}$ during weeks $2-24$ after the index date. Patients in these analyses were censored if at least 5 continuous weeks passed with no platelet count measurement during weeks 2-24 after index date (equating to a minimum of four platelet measurements per patient over the follow-up period). Additionally, durable platelet response was defined as $\geq 75 \%$ of all recorded platelet count measurements $\geq 50 \times 10^{9} / \mathrm{L}$ during weeks $14-24$ after the index date; rescue therapy was treated as outcome failure.

Bleeding outcomes included any bleeding event, bleeding requiring hospitalization (hospitalized bleeding), bleeding leading to emergent treatment, and specific types of bleeding (i.e., abnormal vaginal bleeding, central nervous system bleeding with neurologic symptoms, hematemesis, hematochezia, hematuria, and/or melena). Documented bleeding events (any), hospitalized bleeding, and specific types of bleeding were assessed from the day after the index date through week 24 . Bleeding leading to emergent treatment was defined as having IVIg, IV anti-D, platelet transfusion, or IV steroids as a treatment within 7 days after the start of the bleeding event and was assessed from the day after the index date through week 24 .

Discontinuation of concomitant ITP treatment was defined as a patient having no further administration of any type of non-romiplostim ITP medication that was present at romiplostim initiation (including cyclosporin, mycophenolate mofetil, oral steroid, IV steroid, IVIg, IV anti-D, danazol, vinca alkaloids, azathioprine, rituximab, alemtuzumab, dapsone, cyclophosphamide) during weeks 14-24 after the index date. Discontinuation of specific concomitant ITP treatment was similarly defined but focused only on oral steroids, IV steroid, IVIg, and/or IV anti-D.

All adverse drug reactions (ADRs) that occurred from the day after the index date through 24 weeks were evaluated. Thrombotic ADRs were included if they occurred from the day after the index date through 24 weeks after initiation and the event included one of the MedDRA embolic and thrombotic event terms used to identify baseline thrombotic events. 
Bone marrow ADRs were reported if they occurred from the day after the index date through 24 weeks after initiation and the event contained the term "myelofibrosis."

\section{Statistical Analyses}

We described the overall and stratified (on ITP duration) cohorts at romiplostim initiation. Categorical data were summarized by the number of patients in each category, while continuous data were summarized using the median unless otherwise specified. Additionally, unweighted mean dose and median platelet count were calculated for each patient over the follow-up period. For each time-to-event outcome (bleeding, splenectomy, and ADRs) and binary outcome (durable platelet response and discontinuation of concomitant ITP treatments), we estimated the cumulative incidence of the event for the single treatment group at 24 weeks using the Aalen-Johansen estimator of cumulative incidence accounting for the competing risk of death [9]. We used inverse probability of censoring weights to account for informative censoring [10, 11], and included clinically relevant variables in the censoring models, including severity of thrombocytopenia, number of prior ITP treatments, and history of oral steroid and IVIg use. Patients with missing baseline platelet information $(n=3)$ were dropped from the outcome analyses. Confidence intervals for all outcomes were obtained by taking the standard deviation of the estimates from 100 nonparametric groupbased bootstrap replications. Within each bootstrap replication, the censoring model was re-estimated [12]. The Independent Advarra IRB approved this secondary analysis for NoviSci under NoviSci-01, Pharmacoepidemiology, Health Services, and Outcomes Research Using Limited and De-identified Data (Pro00020889). All analyses were conducted using the open source programming language R v.3.5.2 [13].

\section{RESULTS}

Overall, 340 patients were enrolled in the study, representing adults with primary ITP who received at least one dose of romiplostim [6]. Four patients died during the study and one patient withdrew consent during the 24-week follow-up. Sixty-four (19\%) patients had newly diagnosed ITP, 50 (15\%) had persistent ITP and 226 (66\%) had chronic ITP at romiplostim initiation (Table 1). Patients with newly diagnosed ITP were older than patients with persistent or chronic ITP (median age $=67,59,60$ years, respectively). Median baseline platelet counts were similar across strata, ranging from 17 to $21 \times 10^{9} / \mathrm{L}$. A higher proportion of patients with newly diagnosed ITP at romiplostim initiation had a history of bleeding in the 6 months prior to initiation $(75 \%$ compared to $50 \%$ and $39 \%$ for persistent and chronic ITP, respectively). These patients also more frequently had active bleeding at romiplostim initiation [25\% compared to $8 \%$ (persistent) and $12 \%$ (chronic)].

Regarding the nature and extent of ITP treatments prior to romiplostim initiation, most patients (more than 60\%) had previous exposure to oral steroids or IVIg, regardless of the duration of ITP at romiplostim initiation (Table 1). Forty-five percent of newly diagnosed patients $(n=29), 60 \%$ of persistent $(n=30)$, and $76 \%$ of chronic ITP patients $(n=172)$ were considered refractory at romiplostim initiation (Table S5), and all analyses were repeated using only refractory patients (Tables S6-S9). Prior IV steroid administration and receipt of a platelet transfusion at romiplostim initiation was highest in patients with newly diagnosed ITP (48\% and $36 \%$, respectively), and was lowest in those with chronic ITP (27\% and $12 \%$, respectively). Conversely, previous receipt of splenectomy was most frequent in patients with chronic ITP: $47 \%$ of chronic ITP patients were splenectomized versus $8 \%$ of newly diagnosed or persistent ITP patients initiating romiplostim. Prior rituximab use was also relatively common, particularly in patients with persistent (48\%) or chronic (44\%) ITP at romiplostim initiation. Overall, the number of ITP treatments received prior to romiplostim initiation increased with increasing duration of ITP. However, concomitant treatments at romiplostim initiation was highest in those with newly diagnosed ITP at romiplostim initiation, namely with respect to 
Table 1 Baseline $e^{a}$ characteristics at romiplostim initiation, overall and stratified by duration of ITP at romiplostim initiation

\begin{tabular}{|c|c|c|c|c|}
\hline & \multirow{2}{*}{$\begin{array}{l}\text { Overall } \\
(n=340)\end{array}$} & \multicolumn{3}{|c|}{ ITP duration (months) } \\
\hline & & $\begin{array}{l}<3 \\
(n=64)\end{array}$ & $\begin{array}{l}3-12 \\
(n=50)\end{array}$ & $\begin{array}{l}>12 \\
(n=226)\end{array}$ \\
\hline Age, median (min, max) & $62(18,91)$ & $67(19,88)$ & $59(18,82)$ & $60(18,91)$ \\
\hline \multicolumn{5}{|l|}{ Age at romiplostim initiation (years) } \\
\hline $18-64$ & $193(56.8 \%)$ & $29(45.3 \%)$ & $29(58.0 \%)$ & $135(59.7 \%)$ \\
\hline $65-74$ & $72(21.2 \%)$ & $9(14.1 \%)$ & $11(22.0 \%)$ & $52(23.0 \%)$ \\
\hline $75+$ & $75(22.1 \%)$ & $26(40.6 \%)$ & $10(20.0 \%)$ & $39(17.3 \%)$ \\
\hline Male sex & $157(46.2 \%)$ & $30(46.9 \%)$ & $29(58.0 \%)$ & $98(43.4 \%)$ \\
\hline \multicolumn{5}{|l|}{ Year of romiplostim initiation } \\
\hline 2009 & $65(19.1 \%)$ & $7(10.9 \%)$ & $12(24.0 \%)$ & $46(20.4 \%)$ \\
\hline 2010 & $149(43.8 \%)$ & $32(50.0 \%)$ & $15(30.0 \%)$ & $102(45.1 \%)$ \\
\hline 2011 & $71(20.9 \%)$ & $16(25.0 \%)$ & $11(22.0 \%)$ & $44(19.5 \%)$ \\
\hline 2012 & $55(16.2 \%)$ & $9(14.1 \%)$ & $12(24.0 \%)$ & $34(15.0 \%)$ \\
\hline Weight in kilograms at baseline, median (min, $\max$ ) & $75(24,160)$ & $79(45,130)$ & $70(24,120)$ & $75(43,160)$ \\
\hline Missing & $4(1.2 \%)$ & $1(1.6 \%)$ & $1(2.0 \%)$ & $2(0.9 \%)$ \\
\hline History of thrombotic events & $35(10.3 \%)$ & $7(10.9 \%)$ & $4(8.0 \%)$ & $24(10.6 \%)$ \\
\hline History of myocardial infarction & $11(3.2 \%)$ & $2(3.1 \%)$ & $1(2.0 \%)$ & $8(3.5 \%)$ \\
\hline History of liver event ${ }^{\mathrm{b}}$ & $17(5.0 \%)$ & $5(7.8 \%)$ & $2(4.0 \%)$ & $10(4.4 \%)$ \\
\hline Baseline platelet count $\times 10^{9} / \mathrm{L}$, median $(\min , \max )$ & $20(0.0,380)$ & $17(0.0,190)$ & $19(1.0,160)$ & $21(1.0,380)$ \\
\hline Missing & $3(0.9 \%)$ & $0(0 \%)$ & $0(0 \%)$ & $3(1.3 \%)$ \\
\hline \multicolumn{5}{|l|}{ Baseline platelet count } \\
\hline$\leq 15$ & $129(37.9 \%)$ & $30(46.9 \%)$ & $22(44.0 \%)$ & $77(34.1 \%)$ \\
\hline $16-30$ & $104(30.6 \%)$ & $22(34.4 \%)$ & $9(18.0 \%)$ & $73(32.3 \%)$ \\
\hline$>30$ & $104(30.6 \%)$ & $12(18.8 \%)$ & $19(38.0 \%)$ & $73(32.3 \%)$ \\
\hline Missing & $3(0.9 \%)$ & $0(0 \%)$ & $0(0 \%)$ & $3(1.3 \%)$ \\
\hline Duration of ITP (months), median (min, max) & $40(0.0,670)$ & $0.97(0.0,3.0)$ & $5.8(3.0,12)$ & $81(12,670)$ \\
\hline History of bleeding ${ }^{c}$ & $161(47.4 \%)$ & $48(75.0 \%)$ & $25(50.0 \%)$ & $88(38.9 \%)$ \\
\hline Hospitalized bleeding & $85(25.0 \%)$ & $27(42.2 \%)$ & $14(28.0 \%)$ & $44(19.5 \%)$ \\
\hline Active bleeding & $48(14.1 \%)$ & $16(25.0 \%)$ & $4(8.0 \%)$ & $28(12.4 \%)$ \\
\hline
\end{tabular}


Table 1 continued

$$
\begin{aligned}
& \text { Overall } \\
& (n=340)
\end{aligned}
$$

\section{ITP duration (months)}

\begin{tabular}{lll}
\hline$<3$ & $3-12$ & $>12$ \\
$(n=64)$ & $(n=50)$ & $(n=226)$
\end{tabular}

Prior ITP therapies

Oral steroid

IV anti-D

IVIg

IV steroid

Platelet transfusion

History of splenectomy

AHSCT

Azathioprine

Alemtuzumab

Cyclophosphamide

Cyclosporine

Danazol

Dapsone

Mycophenolate

Rituximab

Vinca alkaloids

Number of ITP treatments received prior to romiplostim initiation, median ( $\min , \max )$

Number of previous ITP treatments received category

$$
0
$$$$
1
$$$$
2
$$

\begin{tabular}{|c|c|c|c|}
\hline $253(74.4 \%)$ & $39(60.9 \%)$ & $37(74.0 \%)$ & 177 (78.3\%) \\
\hline $11(3.2 \%)$ & $0(0 \%)$ & $0(0 \%)$ & $11(4.9 \%)$ \\
\hline $239(70.3 \%)$ & $45(70.3 \%)$ & $35(70.0 \%)$ & $159(70.4 \%)$ \\
\hline 107 (31.5\%) & $31(48.4 \%)$ & $16(32.0 \%)$ & $60(26.5 \%)$ \\
\hline 59 (17.4\%) & $23(35.9 \%)$ & $10(20.0 \%)$ & $26(11.5 \%)$ \\
\hline $116(34.1 \%)$ & $5(7.8 \%)$ & $4(8.0 \%)$ & $107(47.3 \%)$ \\
\hline $1(0.3 \%)$ & $0(0 \%)$ & $0(0 \%)$ & $1(0.4 \%)$ \\
\hline $30(8.8 \%)$ & $0(0 \%)$ & $6(12.0 \%)$ & $24(10.6 \%)$ \\
\hline $0(0 \%)$ & $0(0 \%)$ & $0(0 \%)$ & $0(0 \%)$ \\
\hline $23(6.8 \%)$ & $0(0 \%)$ & $2(4.0 \%)$ & $21(9.3 \%)$ \\
\hline $33(9.7 \%)$ & $0(0 \%)$ & $4(8.0 \%)$ & $29(12.8 \%)$ \\
\hline $35(10.3 \%)$ & $1(1.6 \%)$ & $3(6.0 \%)$ & $31(13.7 \%)$ \\
\hline $20(5.9 \%)$ & $0(0 \%)$ & $3(6.0 \%)$ & $17(7.5 \%)$ \\
\hline $6(1.8 \%)$ & $0(0 \%)$ & $1(2.0 \%)$ & $5(2.2 \%)$ \\
\hline $130(38.2 \%)$ & $6(9.4 \%)$ & $24(48.0 \%)$ & $100(44.2 \%)$ \\
\hline $25(7.4 \%)$ & $3(4.7 \%)$ & $3(6.0 \%)$ & $19(8.4 \%)$ \\
\hline $3.0(0.0,9.0)$ & $2.0(0.0,5.0)$ & $3.0(0.0,6.0)$ & $3.0(0.0,9.0$ \\
\hline $13(3.8 \%)$ & $2(3.1 \%)$ & $2(4.0 \%)$ & $9(4.0 \%)$ \\
\hline $62(18.2 \%)$ & $16(25.0 \%)$ & $11(22.0 \%)$ & $35(15.5 \%)$ \\
\hline 77 (22.6\%) & $20(31.2 \%)$ & $9(18.0 \%)$ & $48(21.2 \%)$ \\
\hline $188(55.3 \%)$ & $26(40.6 \%)$ & $28(56.0 \%)$ & $134(59.3 \%)$ \\
\hline $231(67.9 \%)$ & $29(45.3 \%)$ & $30(60.0 \%)$ & $172(76.1 \%)$ \\
\hline
\end{tabular}$$
3+
$$

Number of refractory patients ${ }^{\mathrm{d}}$

ITP immune thrombocytopenia, $I V$ intravenous, $A H S C T$ autologous hematopoietic stem cell transplantation

${ }^{a}$ Medications were considered to be baseline if the start and end date of the medication happened before the index romiplostim date

b Measured in the 5 years before romiplostim initiation

${ }^{c}$ Measured within 6 months before romiplostim initiation

d Patients were considered to have refractory ITP if they (1) were splenectomized prior to romiplostim initiation, or (2) had three or more ITP therapies prior to romiplostim initiation 
Table 2 Concomitant ${ }^{\mathrm{a}}$ treatments (\%), overall and stratified by duration of ITP at romiplostim initiation

\begin{tabular}{|c|c|c|c|c|}
\hline & \multirow{2}{*}{$\begin{array}{l}\text { Overall } \\
(n=340)\end{array}$} & \multicolumn{3}{|c|}{ ITP duration (months) } \\
\hline & & $\begin{array}{l}<3 \\
(n=64)\end{array}$ & $\begin{array}{l}3-12 \\
(n=50)\end{array}$ & $\begin{array}{l}>12 \\
(n=226)\end{array}$ \\
\hline Oral steroid & $120(35.3 \%)$ & $25(39.1 \%)$ & $18(36.0 \%)$ & $77(34.1 \%)$ \\
\hline IV anti-D & $0(0 \%)$ & $0(0 \%)$ & $0(0 \%)$ & $0(0 \%)$ \\
\hline IVIg & $25(7.4 \%)$ & $6(9.4 \%)$ & $4(8.0 \%)$ & $15(6.6 \%)$ \\
\hline IV steroid & $11(3.2 \%)$ & $4(6.2 \%)$ & $2(4.0 \%)$ & $5(2.2 \%)$ \\
\hline Azathioprine & $5(1.5 \%)$ & $1(1.6 \%)$ & $1(2.0 \%)$ & $3(1.3 \%)$ \\
\hline Alemtuzumab & $0(0 \%)$ & $0(0 \%)$ & $0(0 \%)$ & $0(0 \%)$ \\
\hline Cyclophosphamide & $0(0 \%)$ & $0(0 \%)$ & $0(0 \%)$ & $0(0 \%)$ \\
\hline Cyclosporine & $6(1.8 \%)$ & $0(0 \%)$ & $2(4.0 \%)$ & $4(1.8 \%)$ \\
\hline Danazol & $4(1.2 \%)$ & $0(0 \%)$ & $0(0 \%)$ & $4(1.8 \%)$ \\
\hline Dapsone & $4(1.2 \%)$ & $0(0 \%)$ & $0(0 \%)$ & $4(1.8 \%)$ \\
\hline Mycophenolate & $2(0.6 \%)$ & $0(0 \%)$ & $0(0 \%)$ & $2(0.9 \%)$ \\
\hline Rituximab & $7(2.1 \%)$ & $2(3.1 \%)$ & $1(2.0 \%)$ & $4(1.8 \%)$ \\
\hline Vinca alkaloids & $2(0.6 \%)$ & $1(1.6 \%)$ & $0(0 \%)$ & $1(0.4 \%)$ \\
\hline Platelet transfusion & $12(3.5 \%)$ & $6(9.4 \%)$ & $2(4.0 \%)$ & $4(1.8 \%)$ \\
\hline Number of ITP treatments received, median (Min, Max) & $0.0(0.0,5.0)$ & $1.0(0.0,3.0)$ & $0.0(0.0,3.0)$ & $0.0(0.0,5.0)$ \\
\hline \multicolumn{5}{|l|}{ Number of concomitant ITP treatments received category } \\
\hline 0 & $180(52.9 \%)$ & $28(43.8 \%)$ & $26(52.0 \%)$ & $126(55.8 \%)$ \\
\hline 1 & $127(37.4 \%)$ & $28(43.8 \%)$ & $19(38.0 \%)$ & $80(35.4 \%)$ \\
\hline 2 & $30(8.8 \%)$ & $7(10.9 \%)$ & $4(8.0 \%)$ & $19(8.4 \%)$ \\
\hline $3+$ & $3(0.9 \%)$ & $1(1.6 \%)$ & $1(2.0 \%)$ & $1(0.4 \%)$ \\
\hline
\end{tabular}

ITP immune thrombocytopenia, $I V$ intravenous

a Medications were considered concomitant if the index romiplostim date fell between or on the start or end date of the medication

oral steroids, IVIg, IV steroids, and platelet transfusions (Table 2).

\section{Romiplostim Dosing}

Most patients, regardless of duration of ITP, continued receiving romiplostim for the entire 24-week follow-up period (Table 3). Although the most common starting dose was $1 \mu \mathrm{g} / \mathrm{kg}$, a higher proportion of patients with newly diagnosed ITP started on a higher dose (27\% started on a dose of $\geq 3 \mu \mathrm{g} / \mathrm{kg}$ vs. $16 \%$ in persistent or chronic patients). However, these patients had a lower cumulative dose over the follow-up period than those with persistent or chronic ITP (median $=44 \mu \mathrm{g} / \mathrm{kg}$ vs. $59 \mu \mathrm{g} / \mathrm{kg}$ or $53 \mu \mathrm{g} / \mathrm{kg}$, respectively; Figure S1). This is likely because during the follow-up period, the maximum dose over follow-up was higher for patients with persistent and chronic ITP, and a higher proportion of newly diagnosed patients 
Table 3 Romiplostim usage and dosing during follow-up period, overall and stratified by duration of ITP at romiplostim initiation

\begin{tabular}{|c|c|c|c|c|}
\hline & \multirow{2}{*}{$\begin{array}{l}\text { Overall } \\
(n=340)\end{array}$} & \multicolumn{3}{|c|}{ ITP duration (months) } \\
\hline & & $\begin{array}{l}<3 \\
(n=64)\end{array}$ & $\begin{array}{l}3-12 \\
(n=50)\end{array}$ & $\begin{array}{l}>12 \\
(n=226)\end{array}$ \\
\hline \multicolumn{5}{|l|}{ Duration of exposure (weeks) } \\
\hline Mean (SD) & $22(5.9)$ & $20(7.3)$ & $22(6.0)$ & $22(5.4)$ \\
\hline Median (min, $\max )$ & $24(1.0,24)$ & $24(2.0,24)$ & $24(1.0,24)$ & $24(1.0,24)$ \\
\hline \multicolumn{5}{|l|}{ Number of romiplostim administrations } \\
\hline Mean (SD) & $18(7.6)$ & $17(7.8)$ & $18(7.4)$ & $19(7.5)$ \\
\hline Median (min, max) & $22(1.0,46)$ & $21(2.0,25)$ & $23(1.0,24)$ & $22(1.0,46)$ \\
\hline \multicolumn{5}{|l|}{ Cumulative dose $(\mu \mathrm{g} / \mathrm{kg})$} \\
\hline Mean (SD) & $64(52)$ & $52(35)$ & $71(56)$ & $65(55)$ \\
\hline Median (min, max) & $52(1.0,440)$ & $44(4.0,140)$ & $59(1.0,210)$ & $53(1.0,440)$ \\
\hline \multicolumn{5}{|l|}{ Average weekly dose $(\mu \mathrm{g} / \mathrm{kg})^{\mathrm{a}}$} \\
\hline Mean (SD) & $3.0(2.2)$ & $2.8(1.7)$ & $3.2(2.2)$ & $3.0(2.3)$ \\
\hline Median (min, max) & $2.5(0.04,18)$ & $2.4(0.3,10)$ & $2.5(0.2,8.6)$ & $2.5(0.04,18)$ \\
\hline \multicolumn{5}{|l|}{ Initial romiplostim dose, $n(\%)$} \\
\hline $1 \mu \mathrm{g} / \mathrm{kg}$ & $238(70.0 \%)$ & $38(59.4 \%)$ & $32(64.0 \%)$ & $168(74.3 \%)$ \\
\hline $2 \mu \mathrm{g} / \mathrm{kg}$ & $42(12.4 \%)$ & $9(14.1 \%)$ & $10(20.0 \%)$ & $23(10.2 \%)$ \\
\hline$\geq 3 \mu \mathrm{g} / \mathrm{kg}$ & $60(17.6 \%)$ & $17(26.6 \%)$ & $8(16.0 \%)$ & $35(15.5 \%)$ \\
\hline \multicolumn{5}{|l|}{ Maximum dose $(\mu \mathrm{g} / \mathrm{kg})$} \\
\hline$\leq 3$ & $160(47.1 \%)$ & $34(53.1 \%)$ & $17(34.0 \%)$ & $109(48.2 \%)$ \\
\hline $4-9$ & $145(42.6 \%)$ & $26(40.6 \%)$ & $25(50.0 \%)$ & $94(41.6 \%)$ \\
\hline 10 & $35(10.3 \%)$ & $4(6.2 \%)$ & $8(16.0 \%)$ & $23(10.2 \%)$ \\
\hline$>10$ & $0(0 \%)$ & $0(0 \%)$ & $0(0 \%)$ & $0(0 \%)$ \\
\hline Romiplostim discontinuation at week $24, \%$ & $15.8(11.2-20.4)$ & & $19.2(8.8-29.7)$ & $12.5(7.7-17.4)$ \\
\hline
\end{tabular}

$S D$ standard deviation

${ }^{a}$ Average weekly dose was calculated as cumulative dose/duration of exposure and some patients received more than one dose per week

discontinued romiplostim during follow-up. At 1 month after romiplostim initiation, $11 \%$ of newly diagnosed patients had discontinued romiplostim compared with $4 \%$ of persistent and $3 \%$ of chronic patients (Figure S2). At the end of follow-up at 24 weeks, $25 \%$ of newly diagnosed patients, $19 \%$ of persistent patients, and $13 \%$ of chronic patients had discontinued romiplostim (Figure S2; Table 3). 


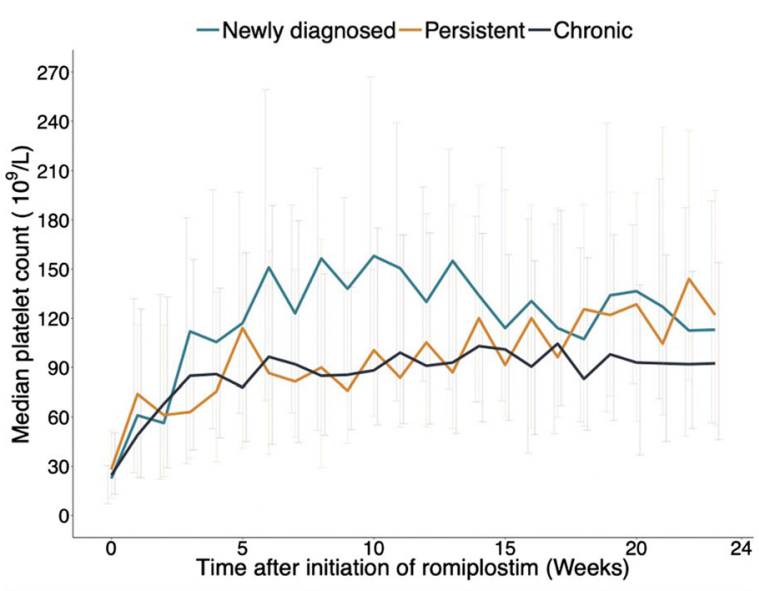

\begin{tabular}{|l|l|l|l|}
\hline N patients & Week 0 & Week 12 & Week 24 \\
\hline Newly diagnosed: $<3$ months & 55 & 43 & 35 \\
\hline Persistent: 3-12 months & 43 & 38 & 27 \\
\hline Chronic: $13+$ months & 192 & 149 & 126 \\
\hline
\end{tabular}

Fig. 1 Unweighted median platelet count by duration of ITP at romiplostim initiation, from initial dose through the 24-week follow-up period. Table represents the number of patients in each strata at week 0 (romiplostim initiation), week 12 , and week 24 of follow-up

\section{Outcomes}

Regardless of ITP duration at romiplostim initiation, more than $80 \%$ of patients achieved a platelet response after romiplostim initiation during the 24-week follow-up (Table S4). Patients with newly diagnosed ITP experienced an increase in platelet count slightly faster than the other groups, but by the end of follow-up the unweighted median platelet count was similar across strata (Fig. 1). The weighted median overall platelet count was $131 \times 10^{9} / \mathrm{L}$ (CI $102-160 \times 10^{9} / \mathrm{L}$ ) for patients with newly diagnosed ITP, $90 \times 10^{9} / \mathrm{L}\left(\mathrm{CI} 60-120 \times 10^{9} / \mathrm{L}\right)$ for patients with persistent ITP, and $88 \times 10^{9} / \mathrm{L}$ $\left(\right.$ CI80-96 $\left.\times 10^{9} / \mathrm{L}\right)$ for patients with chronic ITP. Thirty-two percent (CI 18-46\%) of patients with newly diagnosed ITP, 53\% (CI 37-68\%) of patients with persistent ITP, and 49\% (CI $42-57 \%$ ) of patients with chronic ITP achieved a durable platelet response (Fig. 2). Other plateletbased endpoints followed a similar pattern (Table S4).

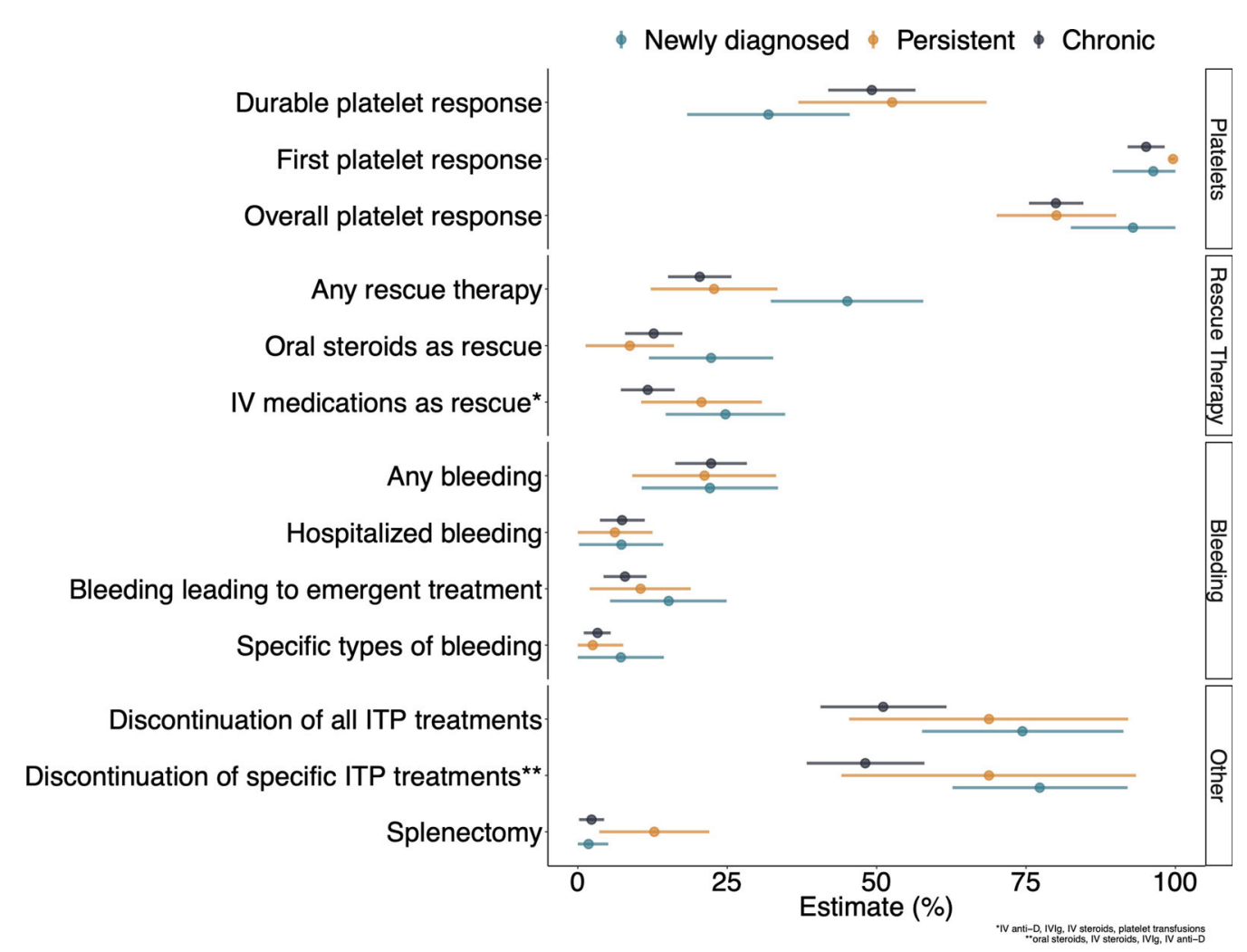

Fig. 2 Estimates of proportion of patients experiencing clinical outcomes by duration of ITP at romiplostim initiation 


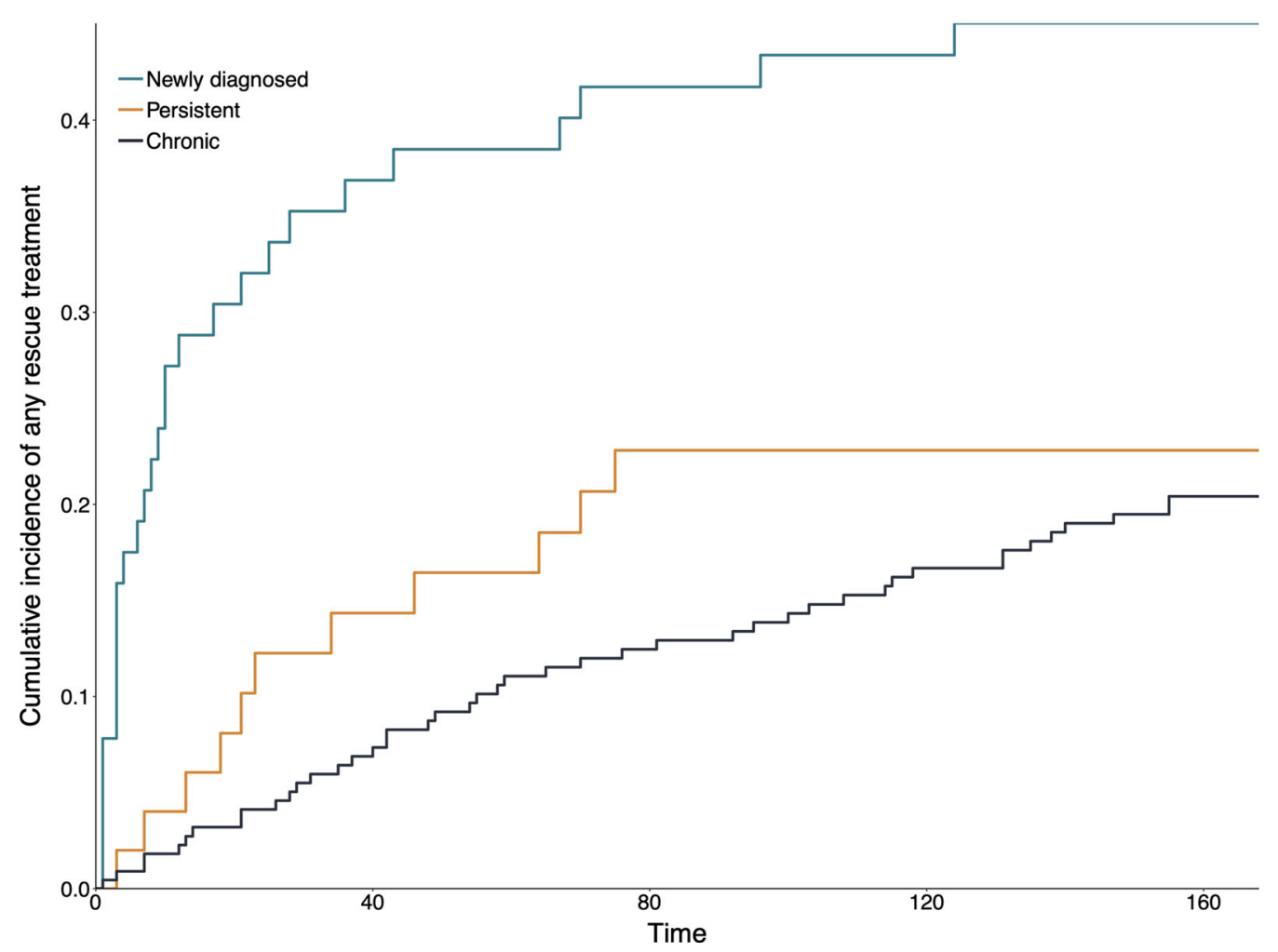

Fig. 3 Cumulative incidence of any rescue treatment, by duration of ITP at romiplostim initiation

Table 4 Adverse drug reactions, overall and stratified by duration of ITP at romiplostim initiation

\begin{tabular}{|c|c|c|c|c|}
\hline & \multirow{2}{*}{$\begin{array}{l}\text { Overall } \\
(n=340)\end{array}$} & \multicolumn{3}{|c|}{ ITP duration (months) } \\
\hline & & $\begin{array}{l}<3 \\
(n=64)\end{array}$ & $\begin{array}{l}3-12 \\
(n=50)\end{array}$ & $\begin{array}{l}>12 \\
(n=226)\end{array}$ \\
\hline Any ADR, \% (95\% CI) & $15.8(12-19.5)$ & $10.9(3.1-18.8)$ & $17(7.3-26.7)$ & $16.7(11.9-21.6)$ \\
\hline Bone marrow ADRs, \% (95\% CI) & $0(0-0)$ & $0(0-0)$ & $0(0-0)$ & $0(0-0)$ \\
\hline Thrombotic ADRs, \% (95\% CI) & $1.3(0-2.6)$ & $1.8(0-5.1)$ & $0(0-0)$ & $1.4(0-3.1)$ \\
\hline
\end{tabular}

$A D R$ adverse drug reaction, $C I 95 \%$ confidence interval

Following romiplostim initiation, $45 \%$ of patients with newly diagnosed ITP, $23 \%$ of patients with persistent ITP, and $20 \%$ of patients with chronic ITP received rescue therapy (Fig. 2). Rescue therapy was administered sooner for newly diagnosed patients; $35 \%$ of patients had received rescue therapy within 30 days following romiplostim initiation (Fig. 3).
Approximately $21-22 \%$ of patients experienced a bleeding event following romiplostim initiation regardless of duration of ITP, and hospitalized bleeding in particular occurred in $6-7 \%$ of patients (Fig. 2; Table S4). Discontinuation of all concomitant ITP medications during weeks 14-24 after romiplostim initiation occurred among $74 \%$ of patients with newly diagnosed ITP, 69\% patients with persistent ITP, 
and $51 \%$ of patients with chronic ITP at initiation. The cumulative incidence of splenectomy following romiplostim initiation was highest among patients with persistent ITP at romiplostim initiation (13\% vs. $2 \%$ in newly diagnosed or chronic ITP patients). An ADR of any type occurred in $11 \%$ of patients with newly diagnosed ITP and $17 \%$ of patients with persistent or chronic ITP during follow-up (Table 4). Thrombotic ADRs were infrequent $(1.8 \%$ in patients with newly diagnosed ITP and $1.4 \%$ in patients with chronic ITP), and there were no bone marrow ADRs.

\section{DISCUSSION}

In this cohort of adults with primary ITP initiating romiplostim in European clinical practice, one-third initiated romiplostim treatment within 12 months following their ITP diagnosis. This is the first study to evaluate real-world patient characteristics, romiplostim dosing, and outcomes stratified by duration of ITP at romiplostim initiation (newly diagnosed, persistent, chronic). Generally, duration of ITP did not appear to affect dosing or response to romiplostim, but newly diagnosed patients in this study had markers of more severe disease at romiplostim initiation, including a higher prevalence of prior and active bleeding and lower platelet counts compared with those with persistent or chronic ITP at romiplostim initiation. In these patients, it is possible that romiplostim was used as an emergency therapy to control bleeding. While the majority of this group had a starting dose of $1 \mu / \mathrm{kg}$, a higher dose of $\geq 3 \mu / \mathrm{kg}$ was not uncommon, and was more frequent than seen in persistent or chronic ITP patients. However, newly diagnosed ITP patients had the lowest cumulative dose over the 24 weeks of follow-up, reflecting a higher incidence of discontinuation in this group. Despite these differences in severity of ITP at romiplostim initiation and romiplostim discontinuation rates during follow-up, platelet responses were similar across strata of ITP duration, and there were few ADRs.

The safety and effectiveness of romiplostim that we observed in routine clinical practice in
Europe is generally consistent with other realworld data studies. Specifically, Lozano et al. [14], found that adverse events were rare in 54 patients using romiplostim in Spain, and Mihaylov et al. [15] found that median platelet count increased in response to romiplostim in 100 patients in Central and Eastern Europe within the first 6 months of treatment. At 24 weeks post-initiation of romiplostim in our study, the weighted median platelet count was similar across ITP duration categories $\left(88-131 \times 10^{9} / \mathrm{L}\right)$. These values are consistent with the median platelet count observed by ITP duration in an integrated analysis of nine clinical trials comparing romiplostim to standard of care or placebo [5]. Among the trial participants, patients who initiated romiplostim with newly diagnosed or persistent primary ITP had median platelet counts ranging from 75 to $120 \times 10^{9} / \mathrm{L}$ during weeks $2-24$ after initiation, while patients with chronic ITP at initiation had counts from 75 to $90 \times 10^{9} / \mathrm{L}$ [5].

After romiplostim initiation, a durable platelet response was achieved in 32\%, 53\%, and $49 \%$ of patients with newly diagnosed, persistent, and chronic ITP, respectively. The response in chronic ITP patients appears comparable to that measured in chronic patients in the aforementioned integrated clinical trial data (49\%), which employed a similar definition of durable platelet response (platelet response for 6 weeks or more during weeks 17-24 after romiplostim initiation) [5]. Among newly diagnosed and persistent ITP patients combined, the integrated analysis demonstrated a durable platelet response of $53 \%$. While our estimate of durable platelet response in persistent patients aligns with this, our estimate in newly diagnosed patients is lower. Given the combined nature of the estimate from the clinical trial data, it is difficult to contextualize our stratified estimates and comment on possible reasons for any differences. One explanation for the lower durable response rate for patients newly diagnosed with ITP could be that newly diagnosed patients in our study had a lower weekly romiplostim dose administered (median weekly dose: $2.4 \mu \mathrm{g} / \mathrm{kg}$ compared with $3.0 \mu \mathrm{g} / \mathrm{kg}$ in the trial data). Additionally, $25 \%$ of newly diagnosed patients in our study discontinued 
romiplostim by 24 weeks, and the majority of these patients discontinued within the first 6 weeks (Figure S2). In contrast, the median duration of exposure among patients in the integrated analysis of trial data was 52 weeks and there were important differences in how the endpoint was operationalized. In the integrated analysis of trial data, missing platelet counts were imputed if the most immediate prior and following measurements were $\geq 50 \times 10^{9} / \mathrm{L}$, and patients who received rescue therapy could contribute to the endpoint after application of an 8-week wash-out period. In our study, patients were censored for missing platelets during specific weeks of follow-up, and we considered rescue therapy as an endpoint failure. These reasons may help explain any differences in the proportions of patients who achieved a durable platelet response in the realworld versus clinical trial setting.

A significant proportion (45\%) of patients with newly diagnosed ITP at romiplostim initiation received rescue therapy during follow-up, and most use occurred within the first month following romiplostim treatment initiation. This could reflect the more severe nature of ITP in these patients at romiplostim initiation (e.g., more active bleeding) compared with those with persistent or chronic ITP. While the integrated analysis of clinical trial data also reported a high proportion of rescue therapy among patients with ITP for 1 year or less $(44 \%)$, our estimates for use among patients with chronic ITP was lower $(20.4 \%$ vs. $50 \%$ in the trials). It should be noted, however, that we were unable to capture any changes in dose or frequency of a specific treatment in our rescue therapy definition, which could explain why some of the estimates in the clinical trial setting were higher.

In our study population, splenectomy occurred relatively infrequently following romiplostim initiation and patients with persistent ITP at initiation were the most likely to undergo this procedure during the 24 weeks of follow-up (13\%). Use of splenectomy in those with either newly diagnosed or chronic ITP at romiplostim initiation was just $2 \%$. Splenectomy has historically been considered the second-line therapy of choice; however, rates have declined in recent years partially due to increased availability of medical options, including thrombopoietin-receptor agonists, romiplostim, and eltrombopag [2, 16, 17]. Notably, $47 \%$ of chronic ITP patients initiating romiplostim were already splenectomized. Given the high proportion of splenectomized patients in the chronic ITP group at romiplostim initiation, and that splenectomy is typically reserved for patients who have had ITP for a certain duration (to allow for potential spontaneous remission) and/or have already received medical alternatives [7, 18], these statistics are not unexpected. Infrequent use of splenectomy following romiplostim initiation has also been observed in clinical practice in the United States [19].

Nearly $75 \%$ of patients with newly diagnosed ITP at romiplostim discontinued all non-romiplostim ITP treatments during weeks 14-24 post-initiation, and over half of patients with persistent or chronic ITP at romiplostim initiation also did so. Given the toxicities associated with many first-line ITP treatment, this is an important finding. For example, in our cohort, over one-third of patients started romiplostim with concomitant oral steroids, regardless of ITP duration. Clinical decision to administer romiplostim early in the course of ITP may have been due to the severity of the presenting symptoms and the desire to limit steroids due to side effects [18]. Known side effects of corticosteroid use includes hypertension, sleep and mood disturbances, gastric irritation or ulcer formation, glaucoma, myopathy, and osteoporosis $[20,21]$, while previous and current clinical guidelines recommend against prolonged use $[18,22]$.

The incidence of ADRs during follow-up did not vary appreciably by ITP duration at romiplostim initiation: ADRs of any type occurred in $11-17 \%$ of patients, thrombotic events were rare, and there were no instances of bone marrow fibrosis. In the clinical trial setting, Kuter et al. (2019) found that serious adverse event rates were similar between newly diagnosed and chronic patients [5]. They considered any event that required or prolonged hospitalization as an adverse event, such as bleeding, dehydration, 
and pyrexia, in addition to any life-threatening condition.

This study has several important limitations. First, this was a descriptive study: no statistical comparisons of outcomes across categories of ITP duration were conducted. It is clear that several baseline characteristics differed by ITP duration, some of which were likely also associated with some of the outcomes. This apparent confounding was not addressed in this descriptive analysis. Second, the data were collected soon after romiplostim was approved in Europe for patients with chronic ITP and before the indication was expanded in Europe to include non-splenectomized patients in 2015 [3]. Therefore, usage patterns and patient characteristics may have changed since the time of data collection. Despite the risk of channeling bias in our data [23], i.e., that patients with worse prognoses may be more likely to be treated with romiplostim, we observed improved effectiveness outcomes. Further, our findings should be generalizable to patients managed in routine care in the European countries participating in this study, but patterns of use of romiplostim may be different in other countries with different prescribing and reimbursement practices. Third, as medical chart review was the primary source of data for this study, some clinical data had limited availability. For example, patients with chronic ITP may have had less complete histories of covariates if their ITP diagnosis predated their available medical record. To limit differential measurement error, we limited the lookback period for important variables (e.g., hospitalized bleeding 6 months before index, liver event occurring in the 5 years before romiplostim initiation). Additionally, the bleeding events reported here likely represent bleeding episodes severe enough to warrant medical care. Chart reviews likely do not capture less severe bleeding, which may not have required medical attention but are important from the patient perspective [24]. Finally, patients with ITP for more than 12 months at romiplostim initiation may represent those with less severe ITP and may be more likely to respond to therapy [25], which could impact future comparative studies. We examined this directly by stratifying by duration of ITP and examining distributions of health and medication variables.

This study builds upon prior real-world evidence of romiplostim use in Europe [6, 14, 15] and prior clinical trial evidence [5] to support the effectiveness and safety in newly diagnosed and persistent ITP patients. Regardless of duration of ITP at romiplostim initiation, in our cohort of adult primary ITP patients being managed in routine European clinical practice, romiplostim effectively raised platelet counts and, importantly, allowed for the discontinuation of other types of ITP treatments not intended for prolonged use. Additionally, the safety profile of romiplostim was consistent across categories of ITP duration and with that demonstrated in the clinical trial setting.

\section{ACKNOWLEDGEMENTS}

Funding. The Rapid Service Fee and the Open Access fee were funded by Amgen.

Authorship. All named authors meet the International Committee of Medical Journal Editors (ICMJE) criteria for authorship for this article, take responsibility for the integrity of the work as a whole, and have given their approval for this version to be published.

Authorship Contributions. All authors critically reviewed results and contributed to the manuscript. Ann Janssens, Tomas Kozak, Helen Papadaki, Georgia Kaiafa, Dominik Selleslag, Jean-Francois Viallard, and Clemens Feistritzer collected data for the study. Melissa Eisen, Michael Kelsh, and Karynsa Kilpatrick conceived of and designed the study and Alan Brookhart, Leah McGrath, and Carrie Nielson conceived of and designed the study as well as conducted analysis and interpretation of data. Alexander Breskin, Bradley Saul, Sara Snell Taylor, and Ying Yu conducted data analyses and interpretation of data and Naufil Alam and Jane Hippenmeyer interpreted data.

Disclosures. Sara Snell Taylor, Alexander Breskin, Leah McGrath, Bradley Saul, and Ying 
$\mathrm{Yu}$ are employees and own equity in NoviSci. Alan Brookhart owns equity in NoviSci, has received research funding from NIH, and in the past 18 months has served as a scientific advisor for AbbVie, Amgen, Atara Biosceience, BlueCross BlueShield North Carolina, Brigham and Women's Hospital, Fibrogen, Genentech, Merck, NC Department of Health and Human Services, and Sanofi Pasteur. Carrie Nielson, Melissa Eisen, Jane Hippenmeyer, Michael Kelsh, and Karynsa Kilpatrick are Amgen employees and own Amgen stock. Naufil Alam was an Amgen employee at the time of writing this manuscript. Helen Papadaki has received research funding from Genesis Pharma and has served as scientific advisor for Gilead and Abbvie. Clemens Feistritzer has served as a scientific advisor for Amgen. Dominik Selleslag received consultancy honoraria from and served on the speaker's bureau of Amgen and Novartis, and is a member of the Belgian Orphan Drug Reimbursement College. Jean-Francois Viallard has received consulting fees for Amgen and Novartis. Ann Janssens, Tomas Kozak and Georgia Kaiafa have nothing to disclose.

Compliance with Ethics Guidelines. This article is based on previously conducted studies and does not contain any new studies with human participants or animals performed by any of the authors.

Data Availability. The datasets analyzed during the current study are available from Amgen on reasonable request.

Open Access. This article is licensed under a Creative Commons Attribution-NonCommercial 4.0 International License, which permits any non-commercial use, sharing, adaptation, distribution and reproduction in any medium or format, as long as you give appropriate credit to the original author(s) and the source, provide a link to the Creative Commons licence, and indicate if changes were made. The images or other third party material in this article are included in the article's Creative Commons licence, unless indicated otherwise in a credit line to the material. If material is not included in the article's Creative Commons licence and your intended use is not permitted by statutory regulation or exceeds the permitted use, you will need to obtain permission directly from the copyright holder. To view a copy of this licence, visit http://creativecommons.org/licenses/by$\mathrm{nc} / 4.0 /$.

\section{REFERENCES}

1. Rodeghiero F, Stasi R, Gernsheimer T, Michel M, Provan D, Arnold DM, et al. Standardization of terminology, definitions and outcome criteria in immune thrombocytopenic purpura of adults and children: report from an international working group. Blood. 2009;113(11):2386-93 (2008/11/14).

2. Lambert MP, Gernsheimer TB. Clinical updates in adult immune thrombocytopenia. Blood. 2017;129(21):2829-35 (2017/04/19).

3. EMA. NPlate Assessment Report [Internet]. 2015. https://www.ema.europa.eu/en/documents/ variation-report/nplate-epar-assessment-reportvariation_en.pdf. Accessed 29 Sep 2020.

4. FDA. Prescribing information for NPlate [Internet]. https://www.accessdata.fda.gov/drugsatfda_docs/ label/2018/125268s163lbl.pdf. Accessed 29 Sep 2020 .

5. Kuter DJ, Newland A, Chong BH, Rodeghiero F, Romero MT, Pabinger I, et al. Romiplostim in adult patients with newly diagnosed or persistent immune thrombocytopenia (ITP) for up to 1 year and in those with chronic ITP for more than 1 year: a subgroup analysis of integrated data from completed romiplostim studies. $\mathrm{Br} \mathrm{J}$ Haematol. 2019;185(3):503-13 (2019/02/23).

6. Steurer M, Quittet P, Papadaki HA, Selleslag D, Viallard JF, Kaiafa G, et al. A large observational study of patients with primary immune thrombocytopenia receiving romiplostim in European clinical practice. Eur J Haematol. 2017;98(2):112-20 $(2016 / 08 / 26)$.

7. Neunert C, Lim W, Crowther M, Cohen A, Solberg L, Crowther MA. The American Society of Hematology 2011 evidence-based practice guideline for immune thrombocytopenia. Blood. 2011;117: 4190-207.

8. Provan D, Stasi R, Newland AC, Blanchette VS, Bolton-Maggs $\mathrm{P}$, Bussel JB, et al. International consensus report on the investigation and management of primary immune thrombocytopenia. Blood. 2010;115(2):168-86 (2009/10/23). 
9. Aalen O. Nonparametric estimation of partial transition probabilities in multiple decrement models. Ann Stat. 1978;6(3):534-45.

10. Cain LE, Cole SR. Inverse probability-of-censoring weights for the correction of time-varying noncompliance in the effect of randomized highly active antiretroviral therapy on incident AIDS or death. Stat Med. 2009;28(12):1725-38.

11. Robins JM, Finkelstein DM. Correcting for noncompliance and dependent censoring in an AIDS clinical trial with inverse probability of censoring weighted (IPCW) log-rank tests. Biometrics. 2000;56(3):779-88 (2000/09/14).

12. Efron B, Tibshirani RJ, Raton B, New L, Washington Y. An introduction to the bootstrap.

13. R Development Core Team. R: a language and environment for statistical computing [Internet]. Vienna, Austria: R Foundation for Statistical Computing; 2017. https://www.r-project.org/.

14. Lozano ML, Mingot-Castellano ME, Perera MM, Jarque I, Campos-Alvarez RM, González-López TJ, et al. Deciphering predictive factors for choice of thrombopoietin receptor agonist, treatment free responses, and thrombotic events in immune thrombocytopenia. Sci Rep. 2019;9(1):1-9.

15. Mihaylov G, Skopec B, Sninska Z, Tzvetkov N, Cerna O, Ivanushkin $V$, et al. PLATON: use of romiplostim to treat chronic primary immune thrombocytopenia: an observational, nonintervention study of real-life practice. Memo Mag Eur Med Oncol. 2020;13(2):227-34.

16. Cetin K, Wetten S, Christiansen C, Norgaard M, Heide-Jorgensen U. Recent time trends in the uptake of splenectomy in adults diagnosed with chronic immune thrombocytopenia: a nationwide historical cohort study in Denmark, 1996-2012. Haematologica. 2015;100(Suppl 1):566.

17. Palandri F, Polverelli N, Sollazzo D, Romano M, Catani L, Cavo M, et al. Have splenectomy rate and main outcomes of ITP changed after the introduction of new treatments? A monocentric study in the outpatient setting during 35 years. Am J Hematol. 2016;91(4):E267-72 (2016/01/23).

18. Neunert C, Terrell DR, Arnold DM, Buchanan G, Cines DB, Cooper N, et al. American Society of Hematology 2019 guidelines for immune thrombocytopenia. Blood Adv. 2019;3(23):3829-66.

19. McGrath LJ, Kilpatrick K, Overman RA, Reams D, Sharma A, Altomare I, et al. Treatment patterns among adults with primary immune thrombocytopenia diagnosed in hematology clinics in the United States. Clin Epidemiol. 2020;12:435-45.

20. Fardet L, Flahault A, Kettaneh A, Tiev KP, Généreau $\mathrm{T}$, Tolédano $\mathrm{C}$, et al. Corticosteroid-induced clinical adverse events: frequency, risk factors and patient's opinion. Br J Dermatol. 2007;157(1):142-8.

21. Judd LL, Schettler PJ, Brown ES, Wolkowitz OM, Sternberg EM, Bender BG, et al. Adverse consequences of glucocorticoid medication: psychological, cognitive, and behavioral effects. Am J Psychiatry. 2014;171:1045-51.

22. Provan D, Arnold DM, Bussel JB, Chong BH, Cooper $\mathrm{N}$, Gernsheimer $\mathrm{T}$, et al. Updated international consensus report on the investigation and management of primary immune thrombocytopenia. Blood Adv. 2019;3:3780-817.

23. Lobo FS, Wagner S, Gross CR, Schommer JC. Addressing the issue of channeling bias in observational studies with propensity scores analysis. Res Soc Adm Pharm. 2006;2(1):143-51 (2006/12/02).

24. Heddle NM, Cook RJ, Webert KE, Sigouin C, Rebulla P. Methodologic issues in the use of bleeding as an outcome in transfusion medicine studies. Transfusion. 2003;43(6):742-52 (2003/05/22).

25. Djulbegovic B, Cohen Y. The natural history of refractory idiopathic thrombocytopenic purpura. Blood. 2001;98(7):2282-3 (2001/10/11). 